\title{
Eukaryotic translation initiation factor 5A in the pathogenesis of cancers (Review)
}

\author{
LIANG NING $^{1}$, LEI WANG ${ }^{2}$, HONGLAI ZHANG $^{2}$, XUELONG JIAO $^{1}$ and DONG CHEN ${ }^{1}$ \\ Departments of ${ }^{1}$ General Surgery and ${ }^{2}$ Thyroid Surgery, \\ The Affiliated Hospital of Qingdao University, Qingdao, Shandong 266003, P.R. China
}

Received March 12, 2020; Accepted June 10, 2020

DOI: $10.3892 / \mathrm{ol} .2020 .11942$

\begin{abstract}
Cancer is the leading cause of death worldwide. The absence of obvious symptoms and insufficiently sensitive biomarkers in early stages of carcinoma limits early diagnosis. Cancer therapy agents and targeted therapy have been used extensively against tissues or organs of specific cancers. However, the intrinsic and/or acquired resistance to the agents or targeted drugs as well as the serious toxic side effects of the drugs would limit their use. Therefore, identifying biomarkers involved in tumorigenesis and progression represents a challenge for cancer diagnosis and therapeutic strategy development. The eukaryotic translation factor 5A (eIF5A), originally identified as an initiation factor, was later shown to promote translation elongation of iterated proline sequences. There are two eIF5A isoforms (eIF5A1 and eIF5A2). eIF5A2 protein consists of 153 residues, and shares $84 \%$ amino acid identity with eIF5A1. However, the biological functions of these two isoforms may be significantly different. Recently, it was demonstrated that eIF5Ais widely involved in the pathogenesis of a number of diseases, including cancers. In particular, eIF5A plays an important role in regulating tumor growth, invasion, metastasis and tumor microenvironment. It was also shown to serve as a potential biomarker and target for the diagnosis and treatment of cancers. The present review briefly discusses the latest findings of eIF5A in the pathogenesis of certain malignant cancers and evolving clinical applications.
\end{abstract}

\section{Contents}

1. Introduction

2. Role of eIF5A in malignant tumors

3. Conclusion

Correspondence to: Dr Xuelong Jiao or Dong Chen, Department of General Surgery, The Affiliated Hospital of Qingdao University, 16 Jiangsu Road, Qingdao, Shandong 266003, P.R. China

E-mail: jiaoxuelong@163.com

E-mail: chendd820@126.com

Key words: eukaryotic translation initiation factor 5A, cancer, apoptosis, proliferation, metastasis

\section{Introduction}

It was estimated that there will be an $\sim 18.1$ million new cancer cases and 9.6 million cancer deaths in 2018 worldwide (1). Lung cancer is a major global health problem, with a poor 5-year survival of $\sim 15 \%$ and is the major cause of cancer-related deaths (2). Diagnosis at an advanced stage is the major reason for this low survival rate (2). Chemotherapy and epidermal growth factor receptor (EGFR) tyrosine kinase inhibitors (TKIs) are used for advanced or recurrent disease, whose efficacy has been limited by emergence of resistance mechanisms (3). Breast, prostate and colorectal cancers are the second, third, and fourth cancers with the highest incidence worldwide, respectively. Colorectal cancer, gastric cancer and hepatocellular carcinoma are the three cancers with the highest mortality rate beyond lung cancer (1). Pancreatic cancer is the seventh leading cause of cancer-related deaths worldwide due to lack of appropriate diagnosis, treatment and cataloging of cancer cases (4). Despite advances in prevention techniques, screening and new technologies in both diagnosis and treatment, incidence and mortality rates continue to rise. Due to the lack of sensitive and specific biomarkers for early cancer detection and proper monitoring of patients' response to therapy (5), the therapeutic effects for invasion-related and metastasis-related cancers are still very poor (6). Therefore, improved tools for diagnosis, treatment and prognosis of cancers are crucial for improving patient outcomes.

The eukaryotic translation initiation factor 5A (eIF5A), the only known protein containing a spermidine derivative, such as hypusine, functions at the level of translation (7). Hypusine is formed by conjugation of the aminobutyl moiety of spermidine to a specific lysine residue of this protein (8). Modification with hypusine is critical requirement for eIF5A activity (9). The post-translational synthesis of hypusine involves two enzymatic steps, catalyzed by deoxyhypusine synthase (DHPS) and deoxyhypusine hydroxylase (DOHH), which selectively uses the polyamine spermidine as a substrate to generate hypusinated eIF5A (10). Two eIF5A isoforms, eIF5A1 and eIF5A2, are generated from distinct but related genes, which in humans contain $84 \%$ amino acid sequence identity (11). eIF5A1 is abundantly expressed in most cells and functions as a translation elongation factor. It was also shown that eIF5A1 is implicated in certain human diseases, including diabetes, several human cancer types, viral 
infections and diseases of the nervous system (12). Meanwhile, eIF5A2 is overexpressed in numerous cancers, expressed few normal tissues, is a candidate oncogene and plays an important role in the development and progression of cancers (13). eIF5A1 does not only act as an oncogene but also functions as a tumor suppressor (14). eIF5A2 acts as an oncogene in several cancers (13). Both eIF5A1 and eIF5A2 are involved in cancer development and progression and can be a useful marker for diagnosis and prognosis (14). eIF5A1 and eF5A2 exert their roles in promoting cancer cell growth, invasion and metastasis ability via a variety of cellular processes (15). The exact molecular mechanisms of these two proteins in cancer development and progression still remain unclear. One potential mechanism may be implicated in translational control of specific mRNAs, since more reports disclosed that eIF5A1 can promote the translation elongation of mRNA with ribosome stalling motifs (16-18), and it was also revealed that eIF5A1 can promote the translation of mRNA by promoting its nuclear export (19). Another potential mechanism is as a transcription factor in the nucleus, eIF5A2 was observed to bind to the promoter region of hypoxia-inducible factor (HIF) $1 \alpha$ and regulate HIF1 $\alpha$ transcription in esophageal squamous cell carcinoma (ESCC) cell lines (20).

Inhibition of DHS and DOHH activity also provides the possibility of pharmacological control of eIF5A activity and expression of eIF5A-dependent genes (21-23). These findings suggested that eIF5A is a potential target and biomarker for the diagnosis and prediction of prognosis of malignant tumors. In the present review, the role of eIF5A in tumorigenesis and mechanisms in the pathogenesis of malignancy was evaluated and the specific functions of eIF5A are also briefly discussed. eIF5A is suggested to be a high priority target for cancer therapeutics.

\section{Role of eIF5A in malignant tumors}

Cancerous nervous system diseases. Glioblastoma (GBM). GBM is the most frequently occurring and invariably fatal primary brain tumor in adults (24). Despite a broad range of new and more specific treatment strategies, therapy of glioblastomas remains challenging and tumors relapse in all cases (25). The current treatment strategy for patients with GBM consists of surgery, radiotherapy and chemotherapy, but $<3-5 \%$ of patients survive $>5$ years post-diagnosis (26). Thus, novel therapeutic and diagnostic approaches for GBMs are urgently needed. In an effort to find novel approaches to GBM treatment, recent studies have focused on molecular phenotyping of GBM subtypes to identify new targets for biomarkers and therapeutics (24,27-30).

Altered activities ofeIF5A have been associated with cancer development. eIF5A, as well as the DHS and DOHH, were reported to be highly overexpressed in GBM patient samples, and the majority of the normal/healthy glia cells did not express eIF5A (21), suggesting that eIF5A might be a potential biomarker for GBM. Using an in vitro assay, Preukschas et al (21) found that targeting eIF5A and its hypusine modification with N1-guanyl-1,7-diaminoheptane (GC7) showed a strong antiproliferative effect in GBM cell lines. Although delivery of small interfering RNA (siRNA) to suppress GBM growth is a hurdle due to the critical obstacles of the blood-brain barrier, combined treatment with clinically relevant alkylating agents and GC7 had an additive anti-proliferative effect in GBM cell lines (21). This suggested that pharmacological inhibition of eIF5A may represent a novel concept to treat GBM and may help to substantially improve the clinical course of this tumor.

The protein forkhead box D1 (FOXD1) is an oncogene. Short hairpin RNA-mediated attenuation ofFOXD1 in glioma stem-like cells reduces their clonogenicity in vitro and in vivo (31). The long non-coding RNA FOXD1-AS1 (FOXD1-AS1) is the antisense transcript of the gene encoding for FOXD1. FOXD1-AS1 silencing caused glioma cells to exert suppressive effects in vitro and in vivo via targeting eIF5A, a direct target of FOXD1-AS1 (32). The data further indicated that eIF5A may be a target for glioma treatment.

Neuroblastoma $(\mathrm{NB})$. NB is the most common extracranial solid tumor of childhood that affects the age group $<15$ years (33). Despite intensive multi-modal treatment, NB can spontaneously regress without treatment or actively give rise to metastases, and the 5 -year survival rate remains $<50 \%$ among high-risk patients, characterized by certain features, such as metastasis, $>1$ year of age and amplified MYCN oncogene (40-50\%), despite intensive treatment protocols $(34,35)$. Chimeric monoclonal GD2-specific antibodies, the targeted immunotherapy for NB, is clinically used today. However, acute pain side effect and application limit for large doses limit its clinical application (36). Hence, the search for novel therapeutic targets is crucial. Studies have demonstrated that elevated mRNA levels of the two target enzymes deoxyhypusine synthase (DHPS) and ornithine decarboxylase (ODC) correlate with poor prognosis in patients with NB (37). Targeting eIF5A expression using the DHPS inhibitor GC7 and the ODC inhibitor difluoromethylornithine induced p21/retinoblastoma ( $\mathrm{Rb})$ or p27/Rb-mediated G1 cell cycle arrest and activated caspase-3/7/9-mediated apoptosis in NB cells (38), suggesting that eIF5A is an effective target for improved NB drug therapy.

Digestive system neoplasms. Pancreatic cancer. Pancreatic ductal adenocarcinoma (PDAC) is the fourth-leading cause of cancer-related deaths, with an overall survival rate of $<5 \%$ due to its difficulties in early diagnosis and metastasis (39). PDAC is one of the most chemoresistant cancers, and most available treatments are palliative (40). Therefore, identification of novel diagnostic and prognostic biomarkers and exploring corresponding targeted therapeutic strategies are needed.

Preukschas et al (21) investigated how eIF5A regulated PDAC pathogenesis and found that eIF5A was overexpressed in human PDAC tissues compared with corresponding normal pancreatic duct tissues. The study also found that activated eIF5A1 was upregulated during early stages of PDAC progression in response to KRas activation (21). Furthermore, targeting eIF5A by siRNA or pharmacological inhibition reduces PDAC cell proliferation, migration, invasion, metastasis and orthotopic tumor growth in vitro and in vivo $(23,41)$. Mechanistically, eIF5A mediates PDAC cell migration and invasion by regulating RhoA/Rho-associated protein kinase (ROCK) signaling (23), and by regulating eIF5A-inactive tyrosine-protein kinase PEAK1 (PEAK1)-YAP (Yes-asso ciated protein) signaling to mediate tumorigenicity (42). 
Gemcitabine is the standard chemotherapeutic drug for PDAC treatment, either alone or in combination with other chemotherapeutics (43). However, resistance to gemcitabine is inevitable during the initial phase or during the treatment (43). Wang et al (44) reported that eIF5A2 overexpression is involved in chemoresistance to gemcitabine in PDAC cells and targeting eIF5A2 enhances the sensitivity of PDAC cells to gemcitabine in vitro and in vivo. Moreover, eIF5A-mediated PEAK1 expression enhanced gemcitabine sensitivity in PDAC cells (45). These data indicated that targeting eIF5A2 could provide a unique mechanism for PDAC therapy in the clinic.

Hepatocellular carcinoma (HCC). (HCC) is the fifth most common cancer and one of the top causes of cancer mortality worldwide (46). Treatment options for advanced HCC remain limited and unsuccessful due to the high incidence and metastasis, resulting in poor prognosis (47). Therefore, precise and effective biomarkers are needed for early diagnosis and prognostic estimation.

Lee et al (48) reported that the two isoforms (eIF5A1 and eIF5A2) were expressed in HCC tissues; eIF5A1 overexpression was related with higher numbers of tumor nodules and eIF5A2 overexpression was related with tumor venous infiltration in HCC. Tang et al (49) reported that EIF5A2 mRNA expression was significantly increased in HCC tissues compared with nontumorous tissues; furthermore, metastatic or venous infiltrated HCC tissues showed significantly increased eIF5A2 expression compared with the HCC tissues without metastasis or venous infiltration. In addition, eIF5A2 overexpression was significantly associated with shorter survival time in patients with $\mathrm{HCC}(15,50)$. Although eIF5A1 mRNA was expressed in HCC and non-tumor tissues, eIF5A1 expression is positively correlated to the number of metastatic nodules in HCC (51). Thus, eIF5A1/2 may be potential prognostic and diagnostic markers for HCC. In addition, enforced eIF5A2 expression promoted HCC cell growth and accelerated glucose utilization and lipogenesis rates (47). Enforced eIF5A2 expression also promoted HCC cell metastasis and angiogenesis in vivo via the c-Myc/microRNA (miR/miRNA)-29b axis (52). While targeting eIF5A2 by siRNA decreased cell motility and reduced cell migration via reactive oxygen species (ROS)-related pathways (15), miR-125b can reverse the effect of eIF5A2 in HCC cells (53).

Functional studies found that enforced eIF5A2 expression induced epithelial-mesenchymal transition (EMT) and enhanced the migrative and invasive ability of HCC cells in vitro and tumor metastasis in vivo in an experimental mouse model, while targeting eIF5A2 alleviates the tumorigenic properties of HCC cells in vitro and in vivo by inhibiting EMT $(20,49,51)$. Therefore, eIF5A2 may be a potential therapeutic target for HCC. Wang et al (54) reported that targeting eIF5A2 enhanced the chemosensitivity of HCC cells to 5-fluorouracil (5-FU) by blocking p38 mitogen-activated protein kinase and JNK/c-Jun/matrix metalloproteinase (MMP)-2 signaling.

GC7 is a novel inhibitor of DHS, which is the key enzyme eIF5A2 activation and contributes to eIF5A2 inhibition (55). Accumulating evidence indicated that targeting eIF5A2 with GC7 significantly inhibited cell proliferation and promoted the cytotoxicity of cetuximab and doxorubicin in HCC cells $(56,57)$. This data indicated that targeting eIF5A2 may be a chemotherapeutic strategy for the treatment of HCC.
miRNAs play a vital role in tumor chemoresistance via regulating eIF5A2 expression. Using an miRNA target prediction website, Xue et al (58) reported that the 3'-untranslated region of eIF5A2 was a potential target of miR-9. The study found that miR-9 enhanced the sensitivity of HCC cells to cetuximab via targeting eIF5A2. miR-9 can also enhance the sensitivity of HCC cells to cisplatin by targeting eIF5A2, resulting in inhibition of EMT signaling (59). Moreover, miR-383 underexpression-mediated doxorubicin resistance in HCC cells could be reversed by silencing eIF5A2 (60). The long non-coding RNA termed GAS6 antisense RNA 1 (GAS6-AS1)/miR-585/eIF5A2 pathway plays an important role in HCC progression and could be considered as a potential target for therapeutic approaches in HCC (61). These data indicated that targeting eIF5A2 directly or indirectly may serve as a potential therapeutic approach for $\mathrm{HCC}$ in the future.

Gastric cancer (GC). (GC) is one of the most common cancers with relatively poor prognosis and remains the second leading cause of cancer-related deaths worldwide (62). Abnormal gene or molecule expression is closely related to the occurrence and development of GC (63). Therefore, specific inhibitors or overexpression of these genes or molecules may be promising anticancer drugs for GC.

eIF5A2 was found to be overexpressed in human GC tissues and cell lines using immunohistochemical staining and western blot assays (64-67). Higher eIF5A2 expression was correlated with high $\mathrm{pT} / \mathrm{pN}$ stage and lymphovascular invasion and poor overall survival in these patients with GC $(64,65)$. Moreover, downregulation of eIF5A2 by siRNA was shown to inhibit GC cell proliferation and invasion via upregulating E-cadherin expression and downregulation of vimentin, cyclin D1, cyclin D3, c-Myc and metastasis-associated protein1 (MTA1) expression (65). These data indicated that eIF5A2 may be a prognostic marker and therapeutic target gene for GC.

It has been demonstrated that human miRNA expression contributed to the initiation and progression of GC. Tian et al (68) reported that miR-30b induced cell apoptosis and reduced cell migration and invasion in vitro via targeting eIF5A2 expression in GC cells. Sun et al (69) reported that miR-599 inhibited EMT and metastasis of GC cells in vitro and in vivo via targeting eIF5A2. Zhu et al (70) reported that eIF5A2 regulated cisplatin sensitivity in GC cells in vitro via eIF5A2-mediated EMT, suggesting that eIF5A2 may be a molecular target for anti-tumor therapy.

Colorectal cancer $(C R C)$. CRC is the third leading cause of cancer-related deaths worldwide (71). Despite recent improvements in screening strategies and the development of more effective treatments for CRC, the prognosis of advanced CRC is still poor (72). Therefore, novel methods that would allow early detection and diagnosis of colorectal cancer are required.

eIF5A2 was found to be overexpressed in CRC tissues using an immunohistochemical assay, and higher eIF5A2 expression was correlated with CRC metastasis and short median survival time (73-76).Therefore, eIF5A2 could be as a novel prognostic marker for patients with CRC. eIF5A2 was also overexpressed in CRC cell lines (77), and enforced eIF5A2 expression induced EMT and enhanced cell motility and invasion in CRC cells 
in vitro and lung metastasis in vivo (73). Another study showed that restoration of eIF5A2 in miR-203-overexpressing CRC cells reversed the suppressive effects of miR-203, indicating that eIF5A2 is a direct and functional target of miR-203 (75). Therefore, eIF5A2 could be an effective therapeutic target for CRC.

Esophageal cancer (EC). EC ranks as the sixth most common cause of cancer-related deaths worldwide (78). There are two major histological forms for EC, adenocarcinoma (EAC) and ESCC, the latter of which comprises up to $90 \%$ of EC, and is a common type of EC in developing countries, including China (79). The five-year survival rate for ESCC is $15-25 \%$, mainly due to late diagnosis and propensity for metastasis (20). Therefore, understanding of the molecular mechanisms underlying ESCC progression could improve early diagnosis, treatment strategy and overall prognosis of ESCC.

Reverse transcription-quantitative PCR (RT-qPCR) and immunohistochemical analyses showed that $>40 \%$ of ESCC tissues showed increased eIF5A2 mRNA and protein expression compared with matched nontumor tissues (80). Furthermore, eIF5A2 overexpression was significantly associated with tumor invasion and lymph node metastasis and shorter survival times for patients with ESCC (80). In ESCC cells in vitro and in vivo, enforced eIF5A2 expression induced EMT and enhanced cell migratory and invasive abilities via HIF1 $\alpha$-mediated signaling pathway (20). Yang et al (80) reported that enforced eIF5A2 expression induced chemoresistance of ESCC cells to 5-FU, docetaxel and taxol in vitro, while targeting eIF5A2 could reverse the effect. In addition, eIF5A2 overexpression was related with shorter survival for patients with ESCC who underwent taxane-based chemotherapy after esophagectomy (80). These data indicated that eIF5A2 maybe as an effective biomarker for predicting prognosis and chemotherapy response for patients with ESCC. In addition, based on GSE6188, GSE13937 and GSE43732 microarray assays obtained from the Gene Expression Omnibus database (http://www.ncbi.nlm.nih.gov/geo/), eIF5A2 was overexpressed in EC tissues compared with matched nontumor tissues, suggesting that eIF5A2 could be as a promising biomarker for the diagnosis of esophageal cancer (81). Moghanibashi et al (82) reported that eIF5A1 participated in nucleocytoplasmic transport, which plays a role in esophageal carcinogenesis. However, whether eIF5A1 could be a diagnostic and therapeutic target needs further investigation. In addition, no related research has been found investigating the association between EAC and in the literature.

Breast cancer. Breast cancer is a strong heterogeneous disease, and its pathogenesis remains unclear in most cases (83). More than $90 \%$ of breast cancer-related deaths are associated with metastasis, however, the critical molecular controls underlying tumor metastasis are poorly understood (84). Current treatments for metastatic breast cancer are based on a strategy of systemic chemotherapy and endocrine therapies, but the intrinsic resistance and acquired resistance to chemotherapy and endocrine therapies are inevitable, of which the molecular resistance mechanisms are still unknown (85). Therefore, the identification of metastasis-related factors and molecular resistance mechanisms warrants further investigation.
Liu et al (86) reported that higher eIF5A2 expression correlated with doxorubicin resistance in breast cancer cells and targeting eIF5A 2 could effectively restore the sensitivity of breast cancer cells to doxorubicin treatment in breast cancer cells in vitro and in vivo. Sirtuin 2 (SIRT2) is a cytoplasmic protein in the family of sirtuins that are $\mathrm{NAD}^{+}$-dependent class III histone deacetylases (87). Increasing evidence implied the dynamic role of SIRT2 in regulating tumorigenesis (88-91). Shah et al (92) reported that targeting eIF5A2 using the small molecule inhibitor of SIRT2 reduced cell viability by inhibiting c-Myc expression in human breast cancer cells in vitro. These data indicated that eIF5A could be an effective target for breast cancer therapy. Liu et al (93) reported that eIF5A2 was identified as a candidate target gene of miR-375, which was suggested to serve as a tumor suppressor in breast cancer. However, to the best of our knowledge, the expression of eIF5A in breast cancer tissues and its association with the clinicopathology of patients with breast cancer have not been reported.

Ovarian cancer. The most extensively investigated biomarker for screening of epithelial ovarian cancer (EOC) is serum CA-125, reported to distinguish malignant from benign pelvic masses, monitor therapeutic response and detect recurrent disease $(94,95)$. However, serum CA-125 has only a modest ability to detect early stage ovarian cancer (96). Moreover, CA-125 screening is not reliable enough for routine monitoring (97). In addition, serum CA-125 has very low predictive value and a high false-positive rate in EOC diagnosis $(96,98)$. Therefore, development of improved diagnostic tools for the early detection of ovarian cancer is urgently needed.

eIF5A2 was found to be overexpressed in EOC tissues, especially in the advanced stage of EOC, using tissue microarray and immunohistochemical assays $(99,100)$, suggesting that eIF5A can be useful as stage-specific tissue biomarker for EOC. In addition, patients with EOC with higher eIF5A2 expression has short survival time compared to the EOC patients with lower IF5A2 expression (101), indicating that eIF5A2 could be a prognostic marker for EOC.

Experimental research found that targeting eIF5A2 inhibited cell growth in the ovarian cancer UACC-1598 cell line in vitro and in vivo (100). Furthermore, targeting eIF5A2 using siRNA increased the chemosensitivity of UACC-1598 cells to gemcitabine treatment (102). Further evidence showed that eIF5A also enhanced chemotherapeutic drug- and XPO1 inhibitor-induced ovarian cancer cell apoptosis in vitro and in vivo (103). Using immunohistochemical assays, eIF5A1 was also found to be overexpressed in EOC tissues, and higher eIF5A1 expression was associated with poor survival of EOC patients (104). In addition, enforced eIF5A1 expression enhanced cell proliferative and invasive capabilities in EOC cells, while targeting eIF5A1 could reverse the effect, implying that eIF5A1 is a potential therapeutic target for EOC (105).

Cervical cancer. Cervical cancer is the second most common cancer among females worldwide (106). Patients with advanced or recurrent cervical cancer have poor prognosis, and their 1-year survival of only 10-20\% (107). Platinum-based chemotherapy in metastatic cervical cancer is palliative and associated with median overall survival of 9 months (108). 
Therefore, it is crucial to explore the molecular mechanism of cervical cancer metastasis and to identify new therapeutic targets.

RT-qPCR assay showed that eIF5A2 mRNA levels were significantly higher in cervical cancer tissues compared with paired paratumor tissues (109). Targeting eIF5A2 inhibited cell proliferation and migration, and induced G1 phase cell cycle arrest in HeLa cells in vitro by targeting the RhoA/ROCK pathway (110). Mémin et al (23) reported that silencing of eIF5A2 inhibited proliferation and induced apoptosis in cervical cancer cell in vitro and in vivo, indicating that eIF5A2 is a potential therapeutic target for cervical cancer. eIF5A1 was also upregulated in human cervical cancer tissues compared with adjacent non-cancerous cervix samples (111). Silencing eIF5A1 or DOHH induced apoptosis of human papilloma virus 16 E6-infected cervical cancer cells in vitro (111). Therefore, targeting eIF5A1 may also provide a new approach for preventing and treating cervical cancer.

Yang et al (109) reported that eIF5A2 overexpression was related with higher Fédération Internationale de Gynécologie et d'Obstétrique staging, lymph node metastasis, postoperative recurrence and poor survival in patients with cervical cancer, suggesting that eIF5A2 is a potential prognosis biomarker for cervical cancer.

Lung cancer. Lung cancer is the leading cause of cancer-related deaths worldwide, and non-small cell lung cancer (NSCLC) constitutes $>80-90 \%$ of all lung malignancies (112). Despite advances in treatment options including surgery, radiation, chemotherapy and targeted therapies, the 5-year overall survival rate for patients with metastatic NSCLC is $<5 \%$ (113). In human lung adenocarcinoma, eIF5A2 overexpression was related with positive lymphocytic response and relatively poorer survival of patients (114). Furthermore, tissues with poor differentiation or 12th/13th codon K-Ras mutations or p53 nuclear accumulation showed higher eIF5A2 expression (114), suggesting that eIF5A2 may be as a prognostic marker for lung adenocarcinoma. Jin et al (115) has demonstrated that adenovirus-mediated eIF5A1 overexpression induced apoptosis in A549 cells in vitro and improved the survival time in mice bearing A549 xenograft tumors in vivo, possibly modulated by NF- $\mathrm{kB}$ in a p53-dependent manner (116). However, Taylor et al (117) reported that eIF5A1 induced A549 cell apoptosis via a p38 and JNK/MAP-dependent pathway and ap53-independent pathway,

eIF5A2 was also found to be overexpressed in NSCLC tissues (118); furthermore, eIF5A2 overexpression was related with advanced $\mathrm{T}$ stage and local invasion in patients with NSCLC (118), suggesting that eIF5A2 might serve as a poor prognostic marker. Xu et al (119) reported that eIF5A2 expression was upregulated in A549 cells following human transforming growth factor (TGF)- $\beta 1$ treatment, which induced EMT phenotypical changes, resulting in enhanced tumor invasion and metastatic capabilities. However, eIF5A2 downregulation could reverse the effect of TGF- $\beta 1$ in A549 cells $(119,120)$. In addition, targeting eIF5A2 significantly inhibited cell proliferation and induced apoptosis, and enhanced cisplatin or cetuximab cytotoxicity in NSCLC cells $(121,122)$. In NSCLC cells, eIF5A2 was reported to control cell growth, apoptosis and chemotherapy sensitivity by regulating miR-9 (123-125). These data indicated that eIF5A2 may serve as a therapeutic target for the treatment of NSCLC.

Malignant tumors of the urinary system. Bladder cancer. Bladder cancer is the fourth most common cancer in males and the ninth most common cancer in females in the Western world (126). A total of 70\% patients with bladder cancer present with superficial tumors, and $>30 \%$ of patients present with muscle-invasive disease, resulting in metastasis and ultimately causing death (127). Moreover, 50-70\% of superficial tumors will recur, and $10-20 \%$ of superficial tumors will progress to muscle-invasive disease $(128,129)$. It is difficult to diagnose bladder cancer accurately and sensitively at an early stage due to the lack of disease-specific symptoms (117). The prognosis of muscle-invasive bladder cancer is poor, and recurrence is common after radical surgery or chemotherapy (130). Therefore, the development of molecular assays that could diagnose bladder cancer accurately at an early stage would be a significant advantage. Numerous reports demonstrated that eIF5A2 was overexpressed in bladder cancer tissues by immunohistochemical and enzyme-linked immunosorbent assays (131-135). Bladder cancer tissues with higher eIF5A2 expression predicted short survival using Kaplan Meier curves, recurrence, progression and chemotherapy response $\mathrm{n}$ patients with bladder cancer (131-133). Therefore, eIF5A2 may be a potential marker of bladder cancer diagnosis or progression. Furthermore, eIF5A2 knockdown inhibited cell proliferation and invasion both in vitro and in vivo, whereas eIF5A2 overexpression promoted cell proliferation in vitro $(131,135)$. In addition, targeting eIF5A2 with GC7 enhanced the therapeutic efficacy of doxorubicin in bladder cancer via preventing EMT $(135,136)$, indicating that eIF5A2 may be a potential target for bladder cancer therapy.

Prostate cancer $(\mathrm{PCa})$. PCa is the second most common cancer and the fifth most common cause of cancer-associated mortality worldwide in men (137). PCa is asymptomatic in the early stage of the disease. However, despite significant improvements in early detection due to routine prostate-specific-antigen (PSA) testing, the diagnostic accuracy is $<75 \%$ (138). In addition, whether PSA testing effectively reduces the risk of death from PCa remains controversial. Advocates of testing argue that PSA testing may, in some cases, lower the stage and grade of cancer at diagnosis, and decrease the risk of being diagnosed with metastatic PCa, for which there is no cure (139). However, across the population of asymptomatic men, PSA testing does not decrease all-cause mortality, and some men will progress and develop metastatic disease despite screening and an earlier diagnosis (140). Therefore, it is critical to develop an individualized approach for early detection (141). Anti-androgen therapies are part of the standard of therapeutic regimen for advanced or metastatic PCa (142). However, PCa always develops resistance to androgen deprivation and progresses to castrate-resistant prostate cancer (143). Lu et al (144) reported that eIF5A2 was overexpressed in PCa tissues, and enhanced eIF5A2 expression was related with higher tumor stage, recurrence and short survival, indicating that eIF5A2 expression could be a candidate biomarker for prognosis assessment in prostate cancer. It was found that enforced eIF5A expression promoted prostate epithelial cell proliferation via 
modulation of DOHH expression, which is a specific and direct target of the putative tumor suppressor miR-331-3p and miR-642-5p $(145,146)$. However, whether eIF5A1/2 could be a target for PCa treatment needs further investigation.

Tumor microenvironment. The tumor microenvironment consists of stromal cells, the extracellular matrix and signaling molecules that communicate with cancer cells (147). The normal cellular microenvironment inhibits tumor cell growth, but alterations within the tumor microenvironment affect the regulation of both cancer and stromal cells (148). Most of the signals are related to the tumor microenvironment, such as Notch signaling (149), tumor-associated macrophages and neutrophils (150), CXCL12/CXCR4 (151), tumor-associated macrophages (152), tumor-related exosomes (153), hypoxia-/HIF-1 $\alpha$-driven factors (154) and MMPs (155). These signals have the ability to induce proliferation and inhibit apoptosis, induce angiogenesis and avoid hypoxia to influence the invasive phenotype (156). In addition, the tumor microenvironment is not only influenced by signals from tumor cells, but also stromal components, which contribute to tumor progression and metastasis by affecting cancer cell function $(157,158)$. Therefore, targeting the tumor microenvironment to encapsulate or destroy cancer cells in their local environment has become mandatory for cancer invasion (159). Hence, identification of therapeutic targets and manipulation of the tumor microenvironment could be used as an approach to prevent and treat cancer.

Accumulating studies have demonstrated that eIF5A2 regulated numerous signals related to cell apoptosis, angiogenesis, invasion and metastasis, such as Akt/MMP-2 (160), MTA1 (70), ROS-related pathways (50), HIF1 $\alpha$-mediated signaling pathway (20), (PEAK1) (15) and TGF- $\beta$ (161). eIF5A2 was able to induce EMT in CRC cells, a key event in tumor invasion and metastasis, characterized by downregulation of epithelial markers such as E-cadherin and $\beta$-catenin and upregulation of mesenchymal markers such as fibronectin, $\mathrm{N}$-cadherin, $\alpha$-smooth muscle actin and vimentin (162). In addition, eIF5A2 could also activate RhoA/Racl to stimulate the formation of stress fiber and lamellipodia (17). Therefore, targeting eIF5A2 in the tumor microenvironment could be useful in the treatment and prevention of cancer.

\section{Conclusion}

Accumulative clinical and experimental evidence showed that eIF5A2 is overexpressed in a number of malignant tumor tissues. Upregulation of eIF5A2 is associated with poor survival, advanced disease stage, poor response to chemotherapeutic drugs and metastasis for patients with cancer, suggesting that eIF5A2 might be a potential prognostic biomarker for malignancies. Numerous evidence demonstrated that enforced eIF5A2 expression enhanced cancer cell growth, increased cancer cell metastasis and promoted chemotherapy resistance through multiple ways. Furthermore, targeting eIF5A2 or inactivating hypusination of eIF5A by DHPS and DOHH attenuated tumor growth and metastasis and overcomes chemotherapeutic resistance, suggesting that targeting eIF5A2 may provide an effective approach for the treatment of malignancies. However, the exact mechanism by which eIF5A2 regulates its target genes and whether it can directly play a biological role as a transcription factor has not been elucidated.

\section{Acknowledgements}

The authors would like to thank Professor Kejun Zhang (The Affiliated Hospital of Qingdao University) for his contributions in editing the manuscript.

\section{Funding}

No funding was received.

\section{Availability of data and materials}

Not applicable.

\section{Authors' contributions}

XJ, LW, HZ and LN collaborated in data collection and literature review. DC wrote the manuscript. All authors read and approved the final version of the manuscript.

\section{Ethics approval and consent to participate}

Not applicable.

\section{Patient consent for publication}

Not applicable.

\section{Competing interests}

The authors declare that they have no competing interests.

\section{References}

1. Bray F, Ferlay J, Soerjomataram I, Siegel RL, Torre LA and Jemal A: Global cancer statistics 2018: GLOBOCAN estimates of incidence and mortality worldwide for 36 cancers in 185 countries. CA Cancer J Clin 68: 394-424, 2018.

2. Siegel RL, Miller KD and Jemal A: Cancer statistics, 2018. CA Cancer J Clin 68: 7-30, 2018.

3. Altorki NK, Markowitz GJ, Gao D, Port JL, Saxena A, Stiles B, McGraw T and Mittal V: The lung microenvironment: An important regulator of tumour growth and metastasis. Nat Rev Cancer 19: 9-31, 2019.

4. Rawla P, Sunkara T and Gaduputi V: Epidemiology of pancreatic cancer: Global trends, etiology and risk factors. World J Oncol 10: 10-27, 2019.

5. Vaidyanathan R, Soon RH, Zhang P, Jiang K and Lim CT: Cancer diagnosis: From tumor to liquid biopsy and beyond. Lab Chip 19: 11-34, 2018.

6. Vadlapatla RK, Vadlapudi AD, Pal D and Mitra AK: Mechanisms of drug resistance in cancer chemotherapy: Coordinated role and regulation of efflux transporters and metabolizing enzymes. Curr Pharm Des 19: 7126-7140, 2013.

7. Dever TE, Gutierrez E and Shin BS: The hypusine-containing translation factor eIF5A. Crit Rev Biochem Mol Biol 49: 413-425, 2014.

8. Park MH and Wolff EC: Hypusine, a polyamine-derived amino acid critical for eukaryotic translation. J Biol Chem 293: 18710-18718, 2018

9. Igarashi $\mathrm{K}$ and Kashiwagi $\mathrm{K}$ : The functional role of polyamines in eukaryotic cells. Int J Biochem Cell Biol 107: 104-115, 2019.

10. Turpaev KT: Translation factor eIF5A, modification with hypusine and role in regulation of gene expression. eIF5A as a target for pharmacological interventions. Biochemistry (Mosc) 83: 863-873, 2018. 
11. Jenkins ZA, Hååg PG and Johansson HE: Human eIF5A2 on chromosome $3 \mathrm{q} 25-\mathrm{q} 27$ is a phylogenetically conserved vertebrate variant of eukaryotic translation initiation factor $5 \mathrm{~A}$ with tissue-specific expression. Genomics 71: 101-109, 2001.

12. Wu GQ, Xu YM and Lau ATY: Recent insights into eukaryotic translation initiation factors $5 \mathrm{~A} 1$ and $5 \mathrm{~A} 2$ and their roles in human health and disease. Cancer Cell Int 20: 142, 2020.

13. Mathews MB and Hershey JW: The translation factor eIF5A and human cancer. Biochim Biophys Acta 1849: 836-844, 2015.

14. Caraglia M, Park MH, Wolff EC, Marra M and Abbruzzese A: eIF5A isoforms and cancer: Two brothers for two functions? Amino Acids 44: 103-109, 2013.

15. Cao TT, Lin SH, Fu L, Tang Z, Che CM, Zhang LY, Ming XY, Liu TF, Tang XM, Tan BB, et al: Eukaryotic translation initiation factor 5A2 promotes metabolic reprogramming in hepatocellular carcinoma cells. Carcinogenesis 38: 94-104, 2017.

16. Zhang H, Alsaleh G, Feltham J, Sun Y, Napolitano G, Riffelmacher T, Charles P,Frau L, Hublitz P, YuZ, et al: Polyamines control eIF5A hypusination, TFEB translation, and autophagy to reverse B cell senescence. Mol Cell 76: 110-125.e9, 2019.

17. Lubas M, Harder LM, Kumsta C, Tiessen I, Hansen M, Andersen JS, Lund AH and Frankel LB: eIF5A is required for autophagy by mediating ATG3 translation. EMBO Rep 19: 209-214, 2018

18. Puleston DJ, Buck MD, Klein Geltink RI, Kyle RL, Caputa G, O'Sullivan D, Cameron AM, Castoldi A, Musa Y, Kabat AM, et al: Polyamines and eIF5A hypusination modulate mitochondrial respiration and macrophage activation. Cell Metab 30: 352-363. e8, 2019.

19. Maier B, Ogihara T, Trace AP, Tersey SA, Robbins RD, Chakrabarti SK, Nunemaker CS, Stull ND, Taylor CA, Thompson JE, et al: The unique hypusine modification of eIF5A promotes islet beta cell inflammation and dysfunction in mice. J Clin Invest 120: 2156-2170, 2010.

20. Li Y, Fu L, Li JB, Qin Y, Zeng TT, Zhou J, Zeng ZL, Chen J, Cao TT, Ban X, et al: Increased expression of EIF5A2, via hypoxia or gene amplification, contributes to metastasis and angiogenesis of esophageal squamous cell carcinoma. Gastroenterology 146 : 1701-13.e9, 2014

21. Preukschas M, Hagel C, Schulte A, Weber K, Lamszus K, Sievert H, Pällmann N, Bokemeyer C, Hauber J, Braig M, et al: Expression of eukaryotic initiation factor $5 \mathrm{~A}$ and hypusine forming enzymes in glioblastoma patient samples: Implications for new targeted therapies. PLoS One 7: e43468, 2012.

22. Sievert H, Pällmann N, Miller KK, Hermans-Borgmeyer I, Venz S, Sendoel A, Preukschas M, Schweizer M, Boettcher S, Janiesch PC, et al: A novel mouse model for inhibition of DOHH-mediated hypusine modification reveals a crucial function in embryonic development, proliferation and oncogenic transformation. Dis Model Mech 7: 963-976, 2014

23. Mémin E, Hoque M, Jain MR, Heller DS, Li H, Cracchiolo B, Hanauske-Abel HM, Pe'ery T and Mathews MB: Blocking eIF5A modification in cervical cancer cells alters the expression of cancer-related genes and suppresses cell proliferation. Cancer Res 74: 552-562, 2014

24. Stupp R, Mason WP, van den Bent MJ, Weller M, Fisher B, Taphoorn MJ, Belanger K, Brandes AA, Marosi C, Bogdahn U, etal; European Organisation for Research and Treatment of Cancer Brain Tumor and Radiotherapy Groups; National Cancer Institute of Canada Clinical Trials Group: Radiotherapy plus concomitant and adjuvant temozolomide for glioblastoma. N Engl J Med 352. 987-996, 2005

25. Omuro A and DeAngelis LM: Glioblastoma and other malignant gliomas: A clinical review. JAMA 310: 1842-1850, 2013.

26. Dolecek TA, Propp JM, Stroup NE and Kruchko C: CBTRUS statistical report: Primary brain and central nervous system tumors diagnosed in the United States in 2005-2009. Neuro Oncol 14 (Suppl 5): v1-v49, 2012.

27. Djuric U, Lam KHB, Kao J, Batruch I, Jevtic S, Papaioannou MD and Diamandis P: Defining protein pattern differences among molecular subtypes of diffuse gliomas using mass spectrometry. Mol Cell Proteomics 18: 2029-2043, 2019.

28. Hallal S, Ebrahimkhani S, Shivalingam B, Graeber MB, Kaufman KL and Buckland ME: The emerging clinical potential of circulating extracellular vesicles for non-invasive glioma diagnosis and disease monitoring. Brain Tumor Pathol 36: 29-39, 2019.

29. Kim JE, Patel MA, Mangraviti A, Kim ES, Theodros D, Velarde E, Liu A, Sankey EW, Tam A, Xu H, et al: Combination therapy with anti-PD-1, anti-TIM-3, and focal radiation results in regression of murine gliomas. Clin Cancer Res 23: 124-136, 2017.
30. Park AK, Kim P, Ballester LY, Esquenazi Y and Zhao Z: Subtype-specific signaling pathways and genomic aberrations associated with prognosis of glioblastoma. Neuro Oncol 21: 59-70, 2019

31. Cheng P, Wang J, Waghmare I, Sartini S, Coviello V, Zhang Z, Kim SH, Mohyeldin A, Pavlyukov MS, Minata M, et al: FOXD1-ALDH1A3 signaling is a determinant for the self-renewal and tumorigenicity of mesenchymal glioma stem cells. Cancer Res 76: 7219-7230, 2016.

32. Gao YF, Liu JY, Mao XY, He ZW, Zhu T, Wang ZB, Li X, Yin JY, Zhang W, Zhou HH, et al: LncRNA FOXD1-AS1 acts as a potential oncogenic biomarker in glioma. CNS Neurosci Ther 26: 66-75, 2020.

33. Nakagawara A, Li Y, Izumi H, Muramori K, Inada $\mathrm{H}$ and Nishi M: Neuroblastoma. Jpn J Clin Oncol 48: 214-241, 2018.

34. Whittle SB, Smith V, Doherty E, Zhao S, McCarty S and Zage PE: Overview and recent advances in the treatment of neuroblastoma. Expert Rev Anticancer Ther 17: 369-386, 2017.

35. Park JR, Bagatell R, London WB, Maris JM, Cohn SL, Mattay KK and Hogarty M; COG Neuroblastoma Committee: Children's Oncology Group's 2013 blueprint for research: Neuroblastoma. Pediatr Blood Cancer 60: 985-993, 2013.

36. Yu AL, Gilman AL, Ozkaynak MF, London WB Kreissman SG, Chen HX, Smith M, Anderson B, Villablanca JG, Matthay KK, et al; Children's Oncology Group: Anti-GD2 antibody with GM-CSF, interleukin-2, and isotretinoin for neuroblastoma. N Engl J Med 363: 1324-1334, 2010.

37. Bandino A, Geerts D, Koster J and Bachmann AS: Deoxyhypusine synthase (DHPS) inhibitor GC7 induces p21/Rb-mediated inhibition of tumor cell growth and DHPS expression correlates with poor prognosis in neuroblastoma patients. Cell Oncol (Dordr) 37: 387-398, 2014.

38. Schultz CR, Geerts D, Mooney M, El-Khawaja R, Koster J and Bachmann AS: Synergistic drug combination GC7/DFMO suppresses hypusine/spermidine-dependent eIF5A activation and induces apoptotic cell death in neuroblastoma. Biochem J 475: 531-545, 2018.

39. Sakaguchi T, Valente R, Tanaka K, Satoi S and Del Chiaro M: Surgical treatment of metastatic pancreatic ductal adenocarcinoma: A review of current literature. Pancreatology 19: 672-680, 2019.

40. Mangge H, Niedrist T, Renner W, Lyer S, Alexiou C and Haybaeck J: New diagnostic and therapeutic aspects of pancreatic ductal adenocarcinoma. Curr Med Chem 24: 3012-3024, 2017.

41. Fujimura K, Wang H, Watson Fand Klemke RL: KRASOncoprotein expression is regulated by a self-governing eIF5A-PEAK1 feed-forward regulatory loop. Cancer Res 78: 1444-1456, 2018.

42. Strnadel J, Choi S, Fujimura K, Wang H, Zhang W, Wyse M, Wright T, Gross E, Peinado C, Park HW, et al: eIF5A-PEAK1 signaling regulates YAP1/TAZ protein expression and pancreatic cancer cell growth. Cancer Res 77: 1997-2007, 2017.

43. Amrutkar M and Gladhaug IP: Pancreatic cancer chemoresistance to gemcitabine. Cancers (Basel) 9: 157, 2017.

44. Wang Z, Jiang J, Qin T, Xiao Y and Han L: EIF5A regulates proliferation and chemoresistance in pancreatic cancer through the sHH signalling pathway. J Cell Mol Med 23: 2678-2688, 2019.

45. Yao M, Hong Y, Liu Y, Chen W and Wang W: GC7 enhances the sensitivity of pancreatic ductal adenocarcinoma cells to gemcitabine via the inhibition of eukaryotic translation initiation factor 5A2. Exp Ther Med 14: 2101-2107, 2017.

46. Xie Y and Hepatitis B: Hepatitis B virus-associated hepatocellular carcinoma. Adv Exp Med Biol 1018: 11-21, 2017.

47. El-Serag HB: Hepatocellular carcinoma. N Engl J Med 365: 1118-1127, 2011.

48. Lee NP, Tsang FH, Shek FH, Mao M, Dai H, Zhang C, Dong S, Guan XY, Poon RT and Luk JM: Prognostic significance and therapeutic potential of eukaryotic translation initiation factor 5A (eIF5A) in hepatocellular carcinoma. Int J Cancer 127: 968-976, 2010.

49. Tang DJ, Dong SS, Ma NF, Xie D, Chen L, Fu L, Lau SH, Li Y, Li Y and Guan XY: Overexpression of eukaryotic initiation factor 5A2 enhances cell motility and promotes tumor metastasis in hepatocellular carcinoma. Hepatology 51: 1255-1263, 2010.

50. Liu RR, Lv YS, Tang YX, Wang YF, Chen XL, Zheng XX, Xie SZ, Cai Y, Yu J and Zhang XN: Eukaryotic translation initiation factor 5A2 regulates the migration and invasion of hepatocellular carcinoma cells via pathways involving reactive oxygen species. Oncotarget 7: 24348-24360, 2016.

51. Shek FH, Fatima S and Lee NP: Implications of the use of eukaryotic translation initiation factor 5A (eIF5A) for prognosis and treatment of hepatocellular carcinoma. Int J Hepatol 2012: 760928, 2012. 
52. Bai HY, Liao YJ, Cai MY, Ma NF, Zhang Q, Chen JW, Zhang JX, Wang FW, Wang CY, Chen WH, et al: Eukaryotic initiation factor 5A2 contributes to the maintenance of CD133(+) hepatocellular carcinoma cells via the c-Myc/microRNA-29b axis. Stem Cells 36: 180-191, 2018.

53. Tsang FH, Au V, Lu WJ, Shek FH, Liu AM, Luk JM, Fan ST, Poon RT and Lee NP: Prognostic marker microRNA-125b inhibits tumorigenic properties of hepatocellular carcinoma cells via suppressing tumorigenic molecule eIF5A2. Dig Dis Sci 59: 2477-2487, 2014.

54. Wang FW, Cai MY, Mai SJ, Chen JW, Bai HY, Li Y, Liao YJ, Li CP, Tian XP, Kung HF, et al: Ablation of EIF5A2 induces tumor vasculature remodeling and improves tumor response to chemotherapy via regulation of matrix metalloproteinase 2 expression. Oncotarget 5: 6716-6733, 2014.

55. Balabanov S, Gontarewicz A, Ziegler P, Hartmann U, Kammer W, Copland M, Brassat U, Priemer M, Hauber I, Wilhelm T, et al: Hypusination of eukaryotic initiation factor 5A (eIF5A): A novel therapeutic target in BCR-ABL-positive leukemias identified by a proteomics approach. Blood 109: 1701-1711, 2007.

56. Xue F, Liu Y, Chu H, Wen Y, Yan L, Tang Q, Xiao E, Zhang D and Zhang $\mathrm{H}$ : eIF5A2 is an alternative pathway for cell proliferation in cetuximab-treated epithelial hepatocellular carcinoma. Am J Transl Res 8: 4670-4681, 2016.

57. Lou B, Fan J, Wang K, Chen W, Zhou X, Zhang J, Lin S, Lv F and Chen Y: N1-guanyl-1,7-diaminoheptane (GC7) enhances the therapeutic efficacy of doxorubicin by inhibiting activation of eukaryotic translation initiation factor 5A2 (eIF5A2) and preventing the epithelial-mesenchymal transition in hepatocellular carcinoma cells. Exp Cell Res 319: 2708-2717, 2013.

58. Xue F, Liang Y, Li Z, Liu Y, Zhang H, Wen Y, Yan L, Tang Q, Xiao E and Zhang D: MicroRNA-9 enhances sensitivity to cetuximab in epithelial phenotype hepatocellular carcinoma cells through regulation of the eukaryotic translation initiation factor 5A-2. Oncol Lett 15: 813-820, 2018.

59. Bao Y, Zhang Y, Lu Y, Guo H, Dong Z, Chen Q, Zhang X, Shen W, Chen W and Wang X: Overexpression of microRNA-9 enhances cisplatin sensitivity in hepatocellular carcinoma by regulating EIF5A2-mediated epithelial-mesenchymal transition. Int J Biol Sci 16: 827-837, 2020.

60. Tu C, Chen W, Wang S, Tan W, Guo J, Shao C and Wang W: MicroRNA-383 inhibits doxorubicin resistance in hepatocellular carcinoma by targeting eukaryotic translation initiation factor 5A2. J Cell Mol Med 23: 7190-7199, 2019.

61. Ai J, Sun J, Zhou G, Zhu T and Jing L: Long non-coding RNA GAS6-AS1 acts as a ceRNA for microRNA-585, thereby increasing EIF5A2 expression and facilitating hepatocellular carcinoma oncogenicity. Cell Cycle 19: 742-757, 2020.

62. Strong VE: Progress in gastric cancer. Updates Surg 70: 157-159, 2018.

63. Oue N, Sentani K, Sakamoto N, Uraoka N and Yasui W: Molecular carcinogenesis of gastric cancer: Lauren classification, mucin phenotype expression, and cancer stem cells. Int J Clin Oncol 24: 771-778, 2019.

64. Meng QB, Kang WM, Yu JC, Liu YQ, Ma ZQ, Zhou L, Cui QC and Zhou WX: Overexpression of eukaryotic translation initiation factor 5A2 (EIF5A2) correlates with cell aggressiveness and poor survival in gastric cancer. PLoS One 10: e0119229, 2015.

65. Yang Q, Ye Z, Zhang Q, Zhao Z and Yuan H: Expression of eukaryotic translation initiation factor 5A-2 (eIF5A-2) associated with poor survival in gastric cancer. Tumour Biol 37: 1189-1195, 2016.

66. Wang $\mathrm{X}$, Jin $\mathrm{Y}$, Zhang $\mathrm{H}$, Huang $\mathrm{X}$, Zhang $\mathrm{Y}$ and Zhu J: MicroRNA-599 inhibits metastasis and epithelial-mesenchymal transition via targeting EIF5A2 in gastric cancer. Biomed Pharmacother 97: 473-480, 2018.

67. Hu ML, Xiong SW, Zhu SX, Xue XX and Zhou XD: MicroRNAs in gastric cancer: From bench to bedside. Neoplasma 66: 176-186, 2019.

68. Tian SB, Yu JC, Liu YQ, Kang WM, Ma ZQ, Ye X and Yan C: MiR-30b suppresses tumor migration and invasion by targeting EIF5A2 in gastric cancer. World J Gastroenterol 21: 9337-9347, 2015.

69. Sun J, Xu Z, Lv H, Wang Y, Wang L, Ni Y, Wang X, Hu C, Chen $\mathrm{S}$, Teng F, et al: eIF5A2 regulates the resistance of gastric cancer cells to cisplatin via induction of EMT. Am J Transl Res 10: 4269-4279, 2018.

70. Zhu W, Cai MY, Tong ZT, Dong SS, Mai SJ, Liao YJ, Bian XW, Lin MC, Kung HF, Zeng YX, et al: Overexpression of EIF5A2 promotes colorectal carcinoma cell aggressiveness by upregulating MTA1 through C-myc to induce epithelial-mesenchymaltransition. Gut 61: 562-575, 2012.
71. Takeda H, Kataoka S, Nakayama M, Ali MAE, Oshima H, Yamamoto D, Park JW, Takegami Y, An T, Jenkins NA, et al: CRISPR-Cas9-mediated gene knockout in intestinal tumor organoids provides functional validation for colorectal cancer driver genes. Proc Natl Acad Sci USA 116: 15635-15644, 2019.

72. Yan W and Guo M: Epigenetics of colorectal cancer. Methods Mol Biol 1238: 405-424, 2015.

73. Tunca B, Tezcan G, Cecener G,Egeli U, Zorluoglu A, Yilmazlar T, Ak S, Yerci O, Ozturk E, Umut G, et al: Overexpression of CK20, MAP3K8 and EIF5A correlates with poor prognosis in early-onset colorectal cancer patients. J Cancer Res Clin Oncol 139: 691-702, 2013.

74. Xie D, Ma NF, Pan ZZ, Wu HX, Liu YD, Wu GQ, Kung HF and Guan XY: Overexpression of EIF-5A2 is associated with metastasis of human colorectal carcinoma. Hum Pathol 39: 80-86, 2008.

75. Park JH, Aravind L, Wolff EC, Kaevel J, Kim YS and Park MH: Molecular cloning, expression, and structural prediction of deoxyhypusine hydroxylase: A HEAT-repeat-containing metalloenzyme. Proc Natl Acad Sci USA 103: 51-56, 2006.

76. Deng B, Wang B, Fang J, Zhu X, Cao Z, Lin Q, Zhou L and Sun X: MiRNA-203 suppresses cell proliferation, migration and invasion in colorectal cancer via targeting of EIF5A2. Sci Rep 6: 28301, 2016.

77. Torre LA, Bray F, Siegel RL, Ferlay J, Lortet-Tieulent J and Jemal A: Global cancer statistics, 2012. CA Cancer J Clin 65: 87-108, 2015

78. Wu C, Wang Z, Song X, Feng XS, Abnet CC, He J, Hu N, Zuo XB, Tan W, Zhan Q, et al: Joint analysis of three genome-wide association studies of esophageal squamous cell carcinoma in Chinese populations. Nat Genet 46: 1001-1006, 2014.

79. Pennathur A, Gibson MK, Jobe BA and Luketich JD: Oesophageal carcinoma. Lancet 381: 400-412, 2013.

80. Yang H, Li XD, Zhou Y, Ban X, Zeng TT, Li L, Zhang BZ, Yun J, Xie D, Guan XY, et al: Stemness and chemotherapeutic drug resistance induced by EIF5A2 overexpression in esophageal squamous cell carcinoma. Oncotarget 6: 26079-26089, 2015.

81. Cai X, Yang X, Jin C, Li L, Cui Q, Guo Y, Dong Y, Yang X, Guo L and Zhang M: Identification and verification of differentially expressed microRNAs and their target genes for the diagnosis of esophageal cancer. Oncol Lett 16: 3642-3650, 2018.

82. Moghanibashi M, Rastgar Jazii F, Soheili ZS, Zare M, Karkhane A, Parivar K and Mohamadynejad P: Esophageal cancer alters the expression of nuclear pore complex binding protein Hsc70 and eIF5A-1. Funct Integr Genomics 13: 253-260, 2013.

83. Libson S and Lippman M: A review of clinical aspects of breast cancer. Int Rev Psychiatry 26: 4-15, 2014.

84. Hsieh SM, Lintell NA and Hunter KW: Germline polymorphisms are potential metastasis risk and prognosis markers in breast cancer. Breast Dis 26: 157-162, 2007.

85. Pan ST, Li ZL, He ZX, Qiu JX and Zhou SF: Molecular mechanisms for tumour resistance to chemotherapy. Clin Exp Pharmacol Physiol 43: 723-737, 2016.

86. Liu Y, Du F, Chen W, Yao M, Lv K and Fu P: EIF5A2 is a novel chemoresistance gene in breast cancer. Breast Cancer 22: 602-607, 2015.

87. Schemies J, Sippl W and Jung M: Histone deacetylase inhibitors that target tubulin. Cancer Lett 280: 222-232, 2009.

88. Zhang LL, Zhan L, Jin YD, Min ZL, Wei C, Wang Q, Chen YJ, Wu QM, Hu XM and Yuan Q: SIRT2 mediated antitumor effects of shikonin on metastatic colorectal cancer. Eur J Pharmacol 797: 1-8, 2017.

89. Li Y, Zhang M, Dorfman RG, Pan Y, Tang D, Xu L, Zhao Z, Zhou Q, Zhou L, Wang Y, et al: SIRT2 promotes the migration and invasion of gastric cancer through RAS/ERK/JNK/ MMP-9 pathway by increasing PEPCK1-related metabolism. Neoplasia 20: 745-756, 2018.

90. Fiskus W, Coothankandaswamy V, Chen J, Ma H,Ha K, Saenz DT, Krieger SS, Mill CP, Sun B, Huang P, et al: SIRT2 deacetylates and inhibits the peroxidase activity of peroxiredoxin-1 to sensitize breast cancer cells to oxidant stress-inducing agents. Cancer Res 76: 5467-5478, 2016.

91. Negrón Abril YL, Fernández I and Weiss RS: Assessment of SIRT2 inhibitors in mouse models of cancer. Methods Mol Biol 1983: 151-171, 2019.

92. Shah AA, Ito A, Nakata A and Yoshida M: Identification of a selective SIRT2 inhibitor and its anti-breast cancer activity. Biol Pharm Bull 39: 1739-1742, 2016. 
93. Liu J, Wang P, Zhang P, Zhang X, Du H, Liu Q, Huang B, Qian C, Zhang S, Zhu W, et al: An integrative bioinformatics analysis identified miR-375 as a candidate key regulator of malignant breast cancer. J Appl Genet 60: 335-346, 2019.

94. Meyer T and Rustin GJ: Role of tumour markers in monitoring epithelial ovarian cancer. Br J Cancer 82: 1535-1538, 2000.

95. Partridge E, Kreimer AR, Greenlee RT, Williams C, Xu JL, Church TR, Kessel B, Johnson CC, Weissfeld JL, Isaacs C, et al; PLCO Project Team: Results from four rounds of ovarian cancer screening in a randomized trial. Obstet Gynecol 113: 775-782, 2009.

96. Takahashi K, Shibukawa T, Moriyama M, Shirai T, Kijima S, Iwanari O, Matsunaga I and Kitao M: Clinical usefulness and false-positive results of CA 125 as a tumor marker of ovarian cancer - a study on 674 patients. Jpn J Surg 16: 305-310, 1986.

97. Matulonis UA, Sood AK, Fallowfield L, Howitt BE, Sehouli J and Karlan BY: Ovarian cancer. Nat Rev Dis Primers 2: 16061, 2016.

98. Fahad Ullah M: Breast cancer: Current perspectives on the disease status. Adv Exp Med Biol 1152: 51-64, 2019.

99. Guan XY, Fung JM, Ma NF, Lau SH, Tai LS, Xie D, Zhang Y, $\mathrm{Hu} \mathrm{L}, \mathrm{Wu} \mathrm{QL}$, Fang Y, et al: Oncogenic role of eIF-5A2 in the development of ovarian cancer. Cancer Res 64: 4197-4200, 2004.

100. Yang GF, Xie D, Liu JH, Luo JH, Li LJ, Hua WF, Wu HM, Kung HF, Zeng YX and Guan XY: Expression and amplification of eIF-5A2 in human epithelial ovarian tumors and overexpression of EIF-5A2 is a new independent predictor of outcome in patients with ovarian carcinoma. Gynecol Oncol 112: 314-318, 2009.

101. Chatterjee M, Mohapatra S, Ionan A, Bawa G, Ali-Fehmi R, Wang X, Nowak J, Ye B, Nahhas FA, Lu K, et al: Diagnostic markers of ovarian cancer by high-throughput antigen cloning and detection on arrays. Cancer Res 66: 1181-1190, 2006.

102. Yu L, Zhao Y, Quan C, Ji W, Zhu J, Huang Y, Guan R, Sun D, Jin Y, Meng X, et al: Gemcitabine eliminates double minute chromosomes from human ovarian cancer cells. PLoS One 8: e71988, 2013.

103. Miyake T, Pradeep S, Wu SY, Rupaimoole R, Zand B, Wen Y, Gharpure KM, Nagaraja AS, Hu W, Cho MS, et al: XPO1/CRM1 inhibition causes antitumor effects by mitochondrial accumulation of eIF5A. Clin Cancer Res 21: 3286-3297, 2015.

104.Zhang J, Li X, Liu X, Tian F, Zeng W, Xi X and Lin Y: EIF5A1 promotes epithelial ovarian cancer proliferation and progression. Biomed Pharmacother 100: 168-175, 2018.

105. Vora $\mathrm{C}$ and Gupta $\mathrm{S}$ : Targeted therapy in cervical cancer. ESMO Open 3 (Suppl 1): e000462, 2019.

106. Schiffman M, Castle PE, Jeronimo J, Rodriguez AC and Wacholder S: Human papillomavirus and cervical cancer. Lancet 370: 890-907, 2007.

107. Seol HJ, Ulak R, Ki KD and Lee JM: Cytotoxic and targeted systemic therapy in advanced and recurrent cervical cancer: Experience from clinical trials. Tohoku J Exp Med 232: 269-276, 2014

108. Mabuchi S, Yokoi E, Shimura K, Komura N, Matsumoto Y, Sawada K, Isobe A, Tsutsui T, Kitada F and Kimura T: A phase II study of irinotecan combined with S-1 in patients with advanced or recurrent cervical cancer previously treated with platinum based chemotherapy. Int J Gynecol Cancer 29: 474-479, 2019.

109. Yang SS, Gao Y, Wang DY, Xia BR, Liu YD, Qin Y, Ning XM, Li GY, Hao LX, Xiao M, et al: Overexpression of eukaryotic initiation factor 5A2 (EIF5A2) is associated with cancer progression and poor prognosis in patients with early-stage cervical cancer. Histopathology 69: 276-287, 2016.

110. Liu X, Chen D, Liu J, Chu Z and Liu D: Blocking Modification of eukaryotic initiation $5 \mathrm{~A} 2$ antagonizes cervical carcinoma via inhibition of RhoA/ROCK signal transduction pathway. Technol Cancer Res Treat 16: 630-638, 2017.

111. Liu Z, Teng L, Gao L, Wang H, Su Y and Li J: The role of eukaryotic translation initiation factor 5A-1 (eIF5A-1) gene in HPV 16 E6 induces cell growth in human cervical squamous carcinoma cells. Biochem Biophys Res Commun 504: 6-12, 2018.

112. Hirsch FR, Scagliotti GV, Mulshine JL, Kwon R, Curran WJ Jr, Wu YL and Paz-Ares L: Lung cancer: Current therapies and new targeted treatments. Lancet 389: 299-311, 2017.

113. Arbour KC and Riely GJ: Systemic therapy for locally advanced and metastatic non-small cell lung cancer: A Review. JAMA 322 764-774, 2019

114. Chen G, Gharib TG, Thomas DG, Huang CC, Misek DE, Kuick RD, Giordano TJ, Iannettoni MD, Orringer MB, Hanash SM, et al: Proteomic analysis of eIF-5A in lung adenocarcinomas. Proteomics 3: 496-504, 2003.
115. Jin S, Taylor CA, Liu Z, Sun Z, Ye B and Thompson JE: Suppression of primary and disseminated murine tumor growth with eIF5A1 gene therapy. Gene Ther Mol Biol 12: 207-218, 2008.

116. Chan YY, Chang CS, Chien LH and Wu TF: Apoptotic effects of a high performance liquid chromatography (HPLC) fraction of Antrodia camphorata mycelia are mediated by down-regulation of the expressions of four tumor-related genes in human non-small cell lung carcinoma A549 cell. J Ethnopharmacol 127: 652-661, 2010

117. Taylor CA, Zheng Q, Liu Z and Thompson JE: Role of p38 and JNK MAPK signaling pathways and tumor suppressor p53 on induction of apoptosis in response to Ad-eIF5A1 in A549 lung cancer cells. Mol Cancer 12: 35, 2013.

118. He LR, Zhao HY, Li BK, Liu YH, Liu MZ, Guan XY, Bian XW, Zeng YX and Xie D: Overexpression of eIF5A-2 is an adverse prognostic marker of survival in stage I non-small cell lung cancer patients. Int J Cancer 129: 143-150, 2011.

119. Xu GD, Shi XB, Sun LB, Zhou QY, Zheng DW, Shi HS, Che YL, Wang ZS and Shao GF: Down-regulation of eIF5A-2 prevents epithelial-mesenchymal transition in non-small-cell lung cancer cells. J Zhejiang Univ Sci B 14: 460-467, 2013.

120.Xu G, Yu H, Shi X, Sun L, Zhou Q, Zheng D, Shi H, Li N, Zhang $X$ and Shao G: Cisplatin sensitivity is enhanced in non-small cell lung cancer cells by regulating epithelial-mesenchymal transition through inhibition of eukaryotic translation initiation factor 5A2. BMC Pulm Med 14: 174, 2014.

121. Wang X, Jiang R, Cui EH, Feng WM, Guo HH, Gu DH, Tang CW, Xue T and Bao Y: N1-guanyl-1,7-diaminoheptane enhances the chemosensitivity of NSCLC cells to cetuximab through inhibition of eukaryotic translation initiation factor 5A2 activation. Eur Rev Med Pharmacol Sci 20: 1244-1250, 2016.

122. Pan Q, Sun L, Zheng D, Li N, Shi H, Song J, Shao G and Xu G: MicroRNA-9 enhanced cisplatin sensitivity in nonsmall cell lung cancer cells by regulating eukaryotic translation initiation factor 5A2. Biomed Res Int 2018: 1769040, 2018.

123. Xu G, Shao G, Pan Q, Sun L, Zheng D, Li M, Li N, Shi H and Ni Y: MicroRNA-9 regulates non-small cell lung cancer cell invasion and migration by targeting eukaryotic translation initiation factor 5A2. Am J Transl Res 9: 478-488, 2017.

124. Martínez-Bosch N, Rodriguez-Vida A, Juanpere N, Lloreta J, Rovira A, Albanell J, Bellmunt $\mathbf{J}$ and Navarro P: Galectins in prostate and bladder cancer: Tumorigenic roles and clinical opportunities. Nat Rev Urol 16: 433-445, 2019.

125. Font A, Luque R, Villa JC, Domenech M, Vázquez S, Gallardo E, Virizuela JA, Beato C, Morales-Barrera R, Gelabert A, et al: The challenge of managing bladder cancer and upper tract urothelial carcinoma: A review with treatment recommendations from the Spanish Oncology Genitourinary Group (SOGUG). Target Oncol 14: 15-32, 2019.

126. Siegel R, Ma J, Zou Z and Jemal A: Cancer statistics, 2014. CA Cancer J Clin 64: 9-29, 2014

127. Kaufman DS, Shipley WU and Feldman AS: Bladder cancer. Lancet 374: 239-249, 2009.

128. Malmström PU, Agrawal S, Bläckberg M, Boström PJ, Malavaud B, Zaak D and Hermann GG: Non-muscle-invasive bladder cancer: A vision for the future. Scand J Urol 51: 87-94, 2017.

129. Chou R, Gore JL, Buckley D, Fu R, Gustafson K, Griffin JC, Grusing S and Selph S: Urinary biomarkers for diagnosis of bladder cancer: A systematic review and meta-analysis. Ann Intern Med 163: 922-931, 2015.

130. Anderson B: Bladder cancer: overview and management. Part 2: muscle-invasive and metastatic bladder cancer. Br J Nurs 27: S8-S20, 2018

131. Wei JH, Cao JZ, Zhang D, Liao B, Zhong WM, Lu J, Zhao HW, Zhang JX, Tong ZT, Fan S, et al: EIF5A2 predicts outcome in localised invasive bladder cancer and promotes bladder cancer cell aggressiveness in vitro and in vivo. Br J Cancer 110: $1767-1777,2014$

132. Luo JH, Hua WF, Rao HL, Liao YJ, Kung HF, Zeng YX, Guan XY, Chen W and Xie D: Overexpression of EIF-5A2 predicts tumor recurrence and progression in $\mathrm{pTa} / \mathrm{pT} 1$ urothelial carcinoma of the bladder. Cancer Sci 100: 896-902, 2009.

133. Huang Y, Wei J, Fang Y, Chen Z, Cen J, Feng Z, Lu J, Liang Y, Luo J and Chen W: Prognostic value of AIB1 and EIF5A2 in intravesical recurrence after surgery for bladder carcinoma. Cancer Manag Res 10: 6997-7011, 2018.

134. Fang Y, Cen JJ, Cao JZ, Huang Y, Feng ZH, Lu J, Wei JH, Chen ZH, Liang YP, Liao B, et al: Overexpression of EIF5A2 in upper urinary tract urothelial carcinoma is a new independent prognostic marker of survival. Future Oncol 15: 2009-2018, 2019 . 
135. Chen Z, Yu T, Zhou B, Wei J, Fang Y, Lu J, Guo L, Chen W, Liu ZP and Luo J: Mg(II)-catechin nanoparticles delivering siRNA targeting EIF5A2 inhibit bladder cancer cell growth in vitro and in vivo. Biomaterials 81: 125-134, 2016.

136. Yang J, Yu H, Shen M, Wei W, Xia L and Zhao P. N1-guanyl-1,7-diaminoheptane sensitizes bladder cancer cells to doxorubicin by preventing epithelial-mesenchymal transition through inhibition of eukaryotic translation initiation factor 5A2 activation. Cancer Sci 105: 219-227, 2014.

137. Jemal A, Bray F, Center MM, Ferlay J, Ward E and Forman D: Global cancer statistics. CA Cancer J Clin 61: 69-90, 2011

138. De Visschere PJ, Standaert C, Fütterer JJ, Villeirs GM, Panebianco V, Walz J, Maurer T, Hadaschik BA, Lecouvet FE, Giannarini $\mathrm{G}$, et al: A systematic review on the role of imaging in early recurrent prostate cancer. Eur Urol Oncol 2: 47-76, 2019.

139. Loeb S and Catalona WJ: What to do with an abnormal PSA test. Oncologist 13: 299-305, 2008.

140. Schröder FH, Hugosson J, Carlsson S, Tammela T, Määttänen L, Auvinen A, Kwiatkowski M, Recker F and Roobol MJ: Screening for prostate cancer decreases the risk of developing metastatic disease: Findings from the European Randomized Study of Screening for Prostate Cancer (ERSPC). Eur Urol 62: 745-752, 2012

141. Schröder FH, Hugosson J, Roobol MJ, Tammela TL, Zappa M, Nelen V, Kwiatkowski M, Lujan M, Määttänen L, Lilja H, et al; ERSPC Investigators: Screening and prostate cancer mortality: Results of the European Randomised Study of Screening for Prostate Cancer (ERSPC) at 13 years of follow-up. Lancet 384 2027-2035, 2014.

142. Crawford ED, Heidenreich A, Lawrentschuk N, Tombal B Pompeo AC, Mendoza-Valdes A, Miller K, Debruyne FM and Klotz L: Androgen-targeted therapy in men with prostate cancer: Evolving practice and future considerations. Prostate Cancer Prostatic Dis 22: 24-38, 2019

143. Spratt DE, Alshalalfa M, Fishbane N, Weiner AB, Mehra R, Mahal BA, Lehrer J, Liu Y, Zhao SG, Speers C, et al: Transcriptomic heterogeneity of androgen receptor activity defines a de novo low AR-active subclass in treatment naïve primary prostate cancer. Clin Cancer Res 25: 6721-6730, 2019.

144. Lu J, Zhao HW, Chen Y, Wei JH, Chen ZH, Feng ZH, Huang Y, Chen W, Luo JH and Fang Y: Eukaryotic translation initiation factor $5 \mathrm{~A} 2$ is highly expressed in prostate cancer and predicts poor prognosis. Exp Ther Med 17: 3741-3747, 2019.

145.Epis MR, Giles KM, Barker A, Kendrick TS and Leedman PJ: miR-331-3p regulates ERBB-2 expression and androgen receptor signaling in prostate cancer. J Biol Chem 284: 24696-24704, 2009.

146. Epis MR, Giles KM, Kalinowski FC, Barker A, Cohen RJ and Leedman PJ: Regulation of expression of deoxyhypusine hydroxylase $(\mathrm{DOHH})$, the enzyme that catalyzes the activation of eIF5A, by miR-331-3p and miR-642-5p in prostate cancer cells. J Biol Chem 287: 35251-35259, 2012.
147. Hanahan D and Weinberg RA: Hallmarks of cancer: The next generation. Cell 144: 646-674, 2011.

148. Yamaguchi $\mathrm{H}$ : Pathological roles of invadopodia in cancer invasion and metastasis. Eur J Cell Biol 91: 902-907, 2012.

149. Meurette $O$ and Mehlen P: Notch signaling in the tumor microenvironment. Cancer Cell 34: 536-548, 2018.

150. Kim J and Bae JS: Tumor-associated macrophages and neutrophils in tumor microenvironment. Mediators Inflamm 2016: 6058147, 2016.

151. Meng W, Xue S and Chen Y: The role of CXCL12 in tumor microenvironment. Gene 641: 105-110, 2018.

152. Ngambenjawong C, Gustafson $\mathrm{HH}$ and Pun SH: Progress in tumor-associated macrophage (TAM)-targeted therapeutics. Adv Drug Deliv Rev 114: 206-221, 2017.

153. Chen W, Jiang J, Xia W and Huang J: Tumor-related exosomes contribute to tumor-promoting microenvironment: An immunological perspective. J Immunol Res 2017: 1073947, 2017.

154. Vaupel P and Multhoff G: Hypoxia-/HIF-1 $\alpha$-driven factors of the tumor microenvironment impeding antitumor immune responses and promoting malignant progression. Adv Exp Med Biol 1072: 171-175, 2018.

155. Kessenbrock K, Plaks V and Werb Z: Matrix metalloproteinases: Regulators of the tumor microenvironment. Cell 141: $52-67,2010$

156. Wu T and Dai Y: Tumor microenvironment and therapeutic response. Cancer Lett 387: 61-68, 2017.

157. Denton AE, Roberts EW and Fearon DT: Stromal cells in the tumor microenvironment. Adv Exp Med Biol 1060: 99-114, 2018.

158. Guo S and Deng CX: Effect of stromal cells in tumor microenvironment on metastasis initiation. Int J Biol Sci 14: 2083-2093, 2018.

159. Sounni NE and Noel A: Targeting the tumor microenvironment for cancer therapy. Clin Chem 59: 85-93, 2013

160. Khosravi S, Wong RP, Ardekani GS, Zhang G, Martinka M, Ong CJ and Li G: Role of EIF5A2, a downstream target of Akt, in promoting melanoma cell invasion. Br J Cancer 110: 399-408, 2014.

161. Huang Y, Zhu Q, Lu L, Sun S, Hao F, Zhang J, Liu Z, Miao Y, Jiao X and Chen D: EIF5A2 is highly expressed in anaplastic thyroid carcinoma and is associated with tumor growth by modulating TGF- $\beta$ signals. Oncol Res: Mar 5, 2020. doi: 10.3727/0965 04020X15834065061807.

162. Kolligs FT: An alternative way for epithelial-to-mesenchymal transition in colorectal cancer via EIF5A2? Gut 61: 473-474, 2012.

This work is licensed under a Creative Commons Attribution-NonCommercial-NoDerivatives 4.0 International (CC BY-NC-ND 4.0) License. 